Cite this article:

Retsas A,

Kalogeropoulos K,

Kossioni AE.

The use of rotary instruments

in endodontic therapy of older

dental patients.

Stoma Edu J. 2015;2(1):64-69

\section{THE USE OF ROTARY INSTRUMENTS IN ENDODONTIC THERAPY OF OLDER DENTAL PATIENTS}

https://doi.org/10.25241/stomaeduj.2015.2(1).art.8

\section{Anastassios Retsas ${ }^{1 a}$, Konstantinos Kalogeropoulos ${ }^{2 b}$, Anastassia E. Kossioni ${ }^{3 c^{*}}$ 'General Dental Practitioner,Athens, Greece ${ }^{2}$ Department of Endodontics, Dental School, National and Kapodistrian University of Athens, Greece ${ }^{3}$ Division of Gerodontology, Department of Prosthodontics, Dental School, National and Kapodistrian University of Athens, Greece}

${ }^{a} D D S$

bDDS, MSc, Clinical Instructor 'DDS, MSc, PhD, Assistant Professor
* Corresponding author:

Assistant Professor Anastassia Kossioni, DDS, MSc, PhD, Division of Gerodontology, Department of Prosthodontics,

Dental School, National and Kapodistrian University of Athens, Greece, Thivon 2 Goudi, Athens 11527, Greece. Tel: +302107461212 Fax: +302107461240 , email: akossion@dent.uoa.gr
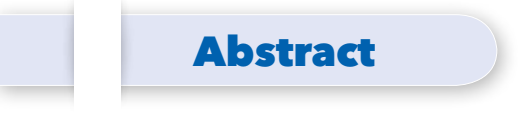

As the older population is continuously growing and many of them retain a significant number of natural teeth, it may be speculated that more endodontic therapies will be performed. The use of rotary instruments constantly grows as they offer many advantages, such as reduction in working time and better preservation of the original root canal morphology. The aim of this study was to discuss the advantages and drawbacks of rotary instrumentation techniques in older patients.

Many older people suffer from significant illnesses restricting access to the dental office and demanding fewer and shorter working sessions. The use of rotary instrumentation may offer a reduction in the number of visits and the duration of the working sessions. They may also help access the root canal system and achieve patency easier and faster, taking into consideration the increased calcification rates and the secondary dentine deposition in older teeth. The drawbacks of the method include increased risk of instrument separation and the possibility of dentine microcracks as its elasticity reduces with ageing.

Rotary systems may be useful tools for the contemporary dental clinician and can offer significant help in many demanding geriatric cases. Nevertheless, they must be cautiously applied after appropriate case selection and familiarisation with their use. More research is necessary on the comparison between the use of rotary instruments and hand files, particularly in older patients.

Keywords: gerodontology, older people, endodontic treatment, rotary instruments

\section{Introduction}

Older persons (aged over 65) (1), unlike in the recent past, can no longer be regarded as de facto edentulous. In many developed or even developing countries an increase in the retention rates of natural teeth in older persons has been recorded over the last decades (2-5). As the older population is continuously growing and many of them retain a significant number of natural teeth, it is expected that more restorative procedures will be needed including endodontic therapies (6). A large number of untreated decayed teeth and few dental visitations for a regular check-up have been recorded in older people in Greece (7) and other countries, indicating a potential increase in the need for endodontic therapy in the near future.

A gradual change in the field of Endodontology, which has become a daily routine, is the use of rotary instruments. Rotary systems in Endodontology have offered many advantages, including reduction in working time $(8,9)$. Moreover, a better preservation of the original root canal morphology can be achieved, as well as a more effective standardisation of its final shape (10). Some years ago, skepticism existed concerning their use (11), but today they are regarded as a necessity rather than a luxury. To the best of our knowledge, the international 


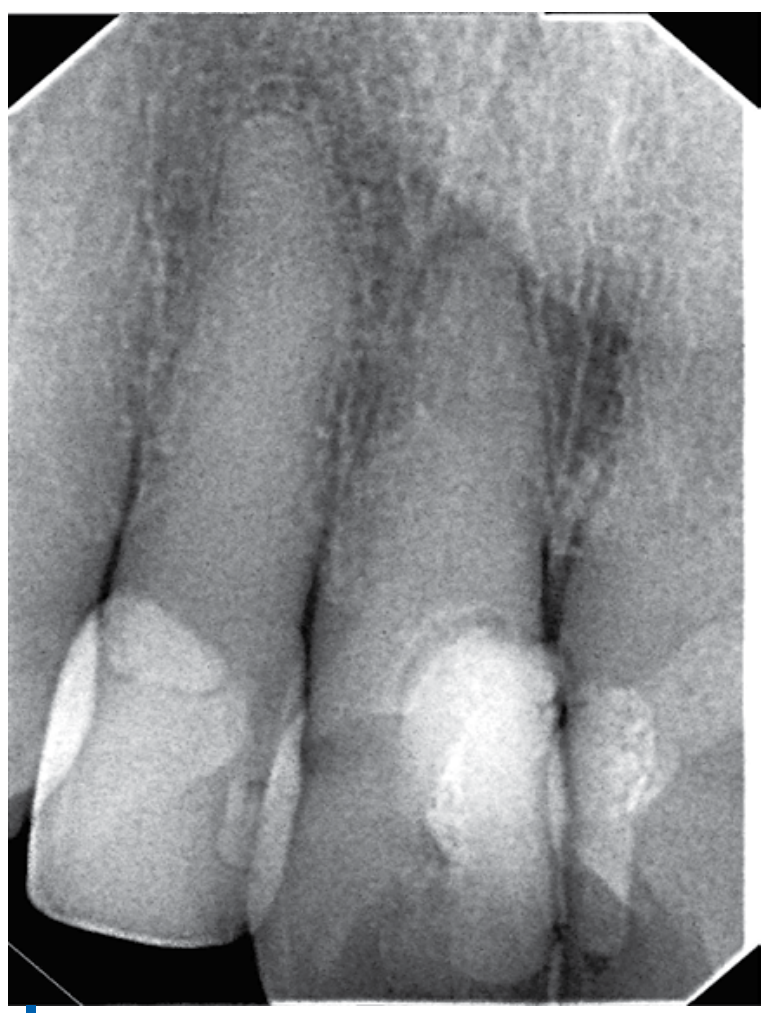

Figure 1. Calcified root canal in an older patient's tooth (\#11) diagnosed with symptomatic apical periodontitis (courtesy of Dr Konstantinos Kalogeropoulos)

bibliography on the specific use of rotary instruments in older patients is very limited.

Ageing is characterised by great biological variability and dental management needs to be individualised and patient-centered. The older dental patients can be generally divided into three groups based on their sociomedical condition that affects clinical decision making:

1. Independent older people, socially active without any significant health problems. They usually belong to the "younger old" group, aged between 65 and 75 years. The dental treatment protocol for these patients does not usually differ from the one applied in younger patients.

2. Frail older people, who are usually medically compromised, receiving a variety of medications and needing external support in their daily life. These patients face difficulties visiting the dental office and are usually accompanied by a carer. They often belong to the "older old" age group (over 75 years of age) and dental treatment is highly individualised.

3. The last group includes the fully dependent geriatric patients, who suffer from increased morbidity and dependency and are usually confined at home, at a nursing home or at hospital. In these patients domiciliary or hospital dental care may be necessary and the treatment options are very limited.

This study refers to the first two groups of patients and the aim is to discuss the advantages and

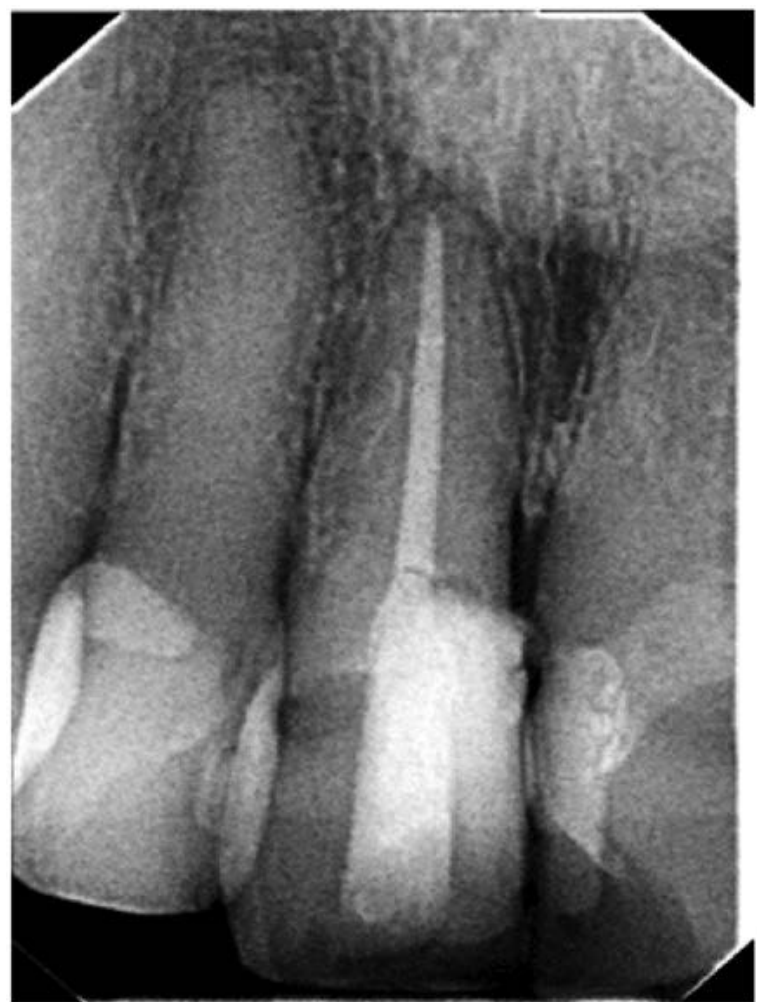

Figure 2. The older patient's tooth (\#11) treated using NiTi rotary instruments (courtesy of

Dr Konstantinos Kalogeropoulos)

drawbacks of rotary instrumentation techniques taking into consideration the specific characteristics of older patients.

\section{Advantages of rotary instrumentation 1.1. Working time reduction}

It has been claimed that geriatric patients often prefer fewer sessions of longer duration rather than multiple but shorter ones (12). Additionally, many clinicians prefer single-visit endodontic treatment over multiple-visits in medically compromised patients (13). Significant barriers to oral care in older people are transportation difficulties (14). On the other hand, on many occasions, it is necessary to organise shorter appointments at specific times of day when the illness is better controlled (i.e. for patients with neurological or cardiovascular disorders) (15).

When the sessions must be kept short or the therapy must be completed in a single appointment, rotary instruments may offer an advantage to the clinician. The use of rotary systems may reduce the duration of mechanical preparation of the root canal system (8), making the endodontic procedure easier for both the patient and the clinician. However, there is lack of published data on the exact time earned through rotary instrumentation during root canal preparation, but it has been mentioned as a side-observation (16). Consequently, better cooperation with the patient and high quality endodontic therapy can be achieved. 


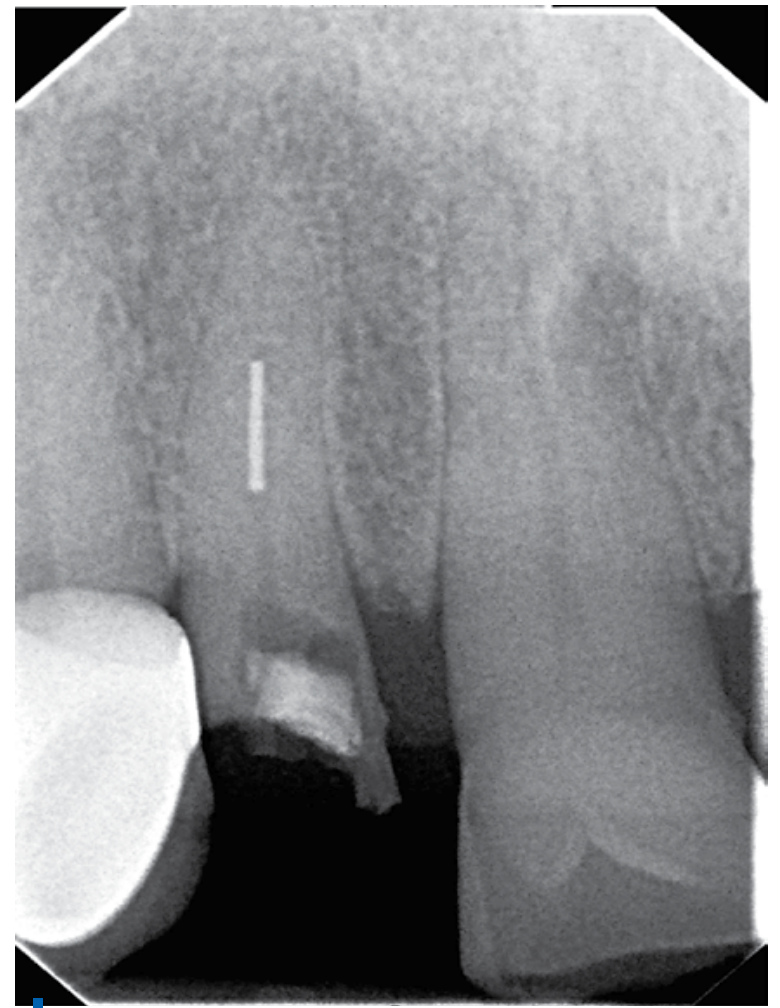

Figure 3. Instrument separation case in an older patient's tooth

It must however always be kept in mind that when a patient is medically compromised, and the basic principles of endodontic therapy cannot be maintained, it would be better to avoid endodontic treatment and modify the treatment plan accordingly (17).

It should be highlighted that the reduction in working time offered by the rotary systems concerns solely the duration of mechanical preparation. A common mistake that needs to be avoided is the omission of an accepted amount of irrigation, for the purpose of chemical disinfection $(18,19)$.

\subsection{Easier access to the root canal system}

The access stage is the most important step in endodontic therapy (20). A common phenomenon with geriatric patients is the obstruction of the root canal orifices, due to the calcific degeneration of the pulp chamber and the tertiary dentine formation $(17,21)$. In many cases, calcification is limited to the cervical third of the canal, resulting in problems mostly in locating and preparing the orifices and not in accessing the apical areas (22).Orifice detection is traditionally achieved with the use of the endodontic explorer DG16. After the orifices have been located, access can be achieved using rotary instruments and more specifically with the help of GG burs, which are recommended by various authors, since the early years of Endodontology (23). Other burs can be used as well, specifically designed for achieving access to calcified orifices, such as the LN burs (Maillefer, Denstply) and the Munce Discovery
Burs (CJM Engineering). The respective use of hand instruments may require extra working time.

\subsection{Achieving patency}

Secondary dentine deposition is continued throughout one's lifespan (24). It is therefore expected that the root canals of elderly patients' teeth are thinner compared to younger patients, to a point that even after accessing them, achieving patency is challenging. Moreover, tertiary dentine is deposited over the root canal walls as a result of the pulp reacting to multiple external stimuli. The root canals in older teeth may be barely visible or not depicted at all when observing the preoperative x-rays (Fig.1). Figures 1 and 2 show an older female patient's tooth (\#11) diagnosed with symptomatic apical periodontitis. The root canal was not visible either radiographically or clinically without microscope magnification (Fig. 1). The preparation was performed using NiTi rotary instruments that helped both achieve patency and shape the canal. Due to the patient's orthopedic problems, the transportation to the dental office was very difficult; therefore the endodontic therapy was completed in a single appointment (Fig. 2).

Patency is usually achieved with the use of small file sizes (ISO \#6, \#8, \#10), with a preference for stainless steel files, due to more effective apical transportation of the applied force. Special files have been developed for this purpose with appropriate design (i.e. PahtfinderS, C Files). However, the use of rotary instruments with specific design to achieve patency in the root canals (i.e. Pathfile, ProGlider, and Dentsply) seems to have simplified the procedure, ensuring acceptable results in less time. The traditional patency achievement with hand files has been occasionally shown to cause significantly greater root canal transportation and infraction of its original morphology as compared to rotary instruments $(25,26)$.

\section{Drawbacks of rotary instrumentation 2.1 Instrument separation}

As mentioned earlier, older patients' teeth often present calcifications. Additionally, root canal wall dentine, due to the physiologic process of sclerosis with aging, displays increased hardness and a high modulus of elasticity (27), which impedes instrument rotation inside the root canal. The root canal size reduction due to deposition of secondary dentine (28), along with the common calcification process, hampers access and obstructs the clinician's visual field. All the abovementioned factors, in addition to the lack of tactile sensation in rotary systems and the increased cutting efficiency compared to hand files, can lead to iatrogenic events, especially in cases of limited familiarity with their use (Fig. 3).

Many clinical studies have focused on the rotary instruments separation and its prevalence 
(29-36), monitoring different systems' behavior and mentioning varying results. The incidence ranges from $1.3 \%-10 \%$ (36) with a mean prevalence of $1.6 \%$ (37). Retrospective clinical studies have shown that the separation incidence for rotary $\mathrm{NiTi}$ instruments is 7 to 8 times greater than that of hand instruments $(38,39)$.

The use of rotary instruments can be significantly improved with the combined use of lubricant agents inside the root canal. These agents facilitate the movement of the instrument inside the narrow environment of the root canal, by decreasing cyclic fatigue and torque load of rotary instruments, especially when they have extra chelating action (40). This way the clinician can handle the rotary instruments more easily and decrease the chance of iatrogenic events and particularly instrument separation. The application of sodium hypochlorite and aqueous chelating solutions (i.e. EDTA) compared to agents in paste form (PC-Prep) has been shown to cause less instruments' fractures (41).

\subsection{Dentine microcracks}

The use of rotary systems for root canal preparation has been related to the creation of deformations and mostly microcracks in

\section{Bibliography}

1. WHO. Definition of an Old or Elderly person (cited 13/5/2015). Available from: http://www. who.int/healthinfo/survey/ageingdefnolder/en.

2. Holst D. Oral health equality during 30 years in Norway. Community Dent Oral Epidemiol. 2008;36(4):326-334.

3. Haisman R, Mason K, Holmes E. Our oral health: Key findings of the 2009 New Zealand Oral Health Survey. Wellington, New Zealand: Ministry of Health, 2010.

4. Petersen PE, Kandelman D, Arpin S, Ogawa H. Global oral health of older people--call for public health action. Community Dent Health. 2010;27(4 Suppl 2):257-267.

5. Kossioni AE. Current status and trends in oral health in the community-dwelling older adults. A global perspective. Oral Health Prev Dent. 2013;11(4):331-340.

6. Walton RE. Endodontic considerations in the geriatric patient. Dent Clin North Am. 1997;41(4):795-816.

7. Oulis C, Theodorou M, Mastrogiannakis $\mathrm{H}$, Mamai-Chomata $\mathrm{H}$, Polychronopoulou A, Athanasoulis T. Oral health status and treatment needs of the Hellenic population. A pathfinder survey. Proposals for improvement. Hell Stomatol Rev. 2009;53(2):97-120. the inner walls of dentine due to tensions' accumulation, especially in the apical third (4244). Similar deformations were not observed after preparation with hand files.

Dentine loses its elasticity with age. Consequently, it is possible that these microcracks appear to greater extend in elderly teeth, which may affect their prognosis and increase the possibility of a root fracture. However, this hypothesis has not yet been confirmed.

\section{Discussion}

The investigation of the existing literature has shown that more research is necessary on the application of rotary systems in older people and more emphasis should be placed on Geriatric Endodontics.

\section{Conclusions}

Rotary systems may be useful tools for the contemporary dental clinician and can offer significant help in many demanding geriatric cases. Nevertheless, they must be cautiously applied after appropriate case selection and familiarisation with their use.

8. Guelzow A, Stamm O, Martus P, Kielbassa AM. Comparative study of six rotary nickel - titanium systems and hand instrumentation for root canal preparation. Int End J. 2005;38:743-752.

9. Kummer TR, Calvo MC, Cordeiro MM, de Sousa Vieira R, de Carvalho Rocha MJ. Ex vivo study of manual and rotary instrumentation techniques in human primary teeth. Oral Surg Oral Med Oral Pathol Oral Radiol Endod. 2008;105(4):e84-92.

10. Gergi R, Rjeily JA, Sader J, Naaman A. Comparison of canal transportation and centering ability of twisted files, Pathfile-ProTaper system, and stainless steel hand K-files by using computed tomography. J Endod. 2010;36(5):904-907.

11. Parashos $\mathrm{P}$, Messer $\mathrm{HH}$. Questionnaire survey on the use of rotary nickel - titanium endodontic instruments by Australian dentists. Int End J. 2004;37(4):249-259.

12. Newton CW, Brown DC. Geriatric Endodontics. In: Cohen S, Burns R, editors: Pathways of the Pulp, 8th SD, Ch.24. St Louis: Mosby 2002.

13. Yap E, Parashos P, Borromeo GL. Root canal treatment and special needs patients. Int End J. 2014;48(4):351-361.

14. Davis DL, Reisine S. Barriers to dental care for older minority adults. Spec Care Dentist. 2015;35(4):182-189. 
15. Kossioni AE. Common diseases among the elderly that affect dental care, 2013. National and Kapodistrian University of Athens, e-class, http:// eclass.uoa.gr/courses/DENT385.

16. Schäfer E, Schulz-Bongert $U$, Tulus G. Comparison of hand stainless steel and nickel titanium rotary instrumentation: a clinical study. J Endod. 2004;30(6):432-435.

17. Allen PF, Whitworth JM. Endodontic considerations in the elderly, Gerodontology. 2004;21(4):185-194.

18. Peters OA, Schonenberger K, Laib A. Effects of four $\mathrm{Ni}-\mathrm{Ti}$ preparation techniques on root canal geometry assessed by micro computed tomography. Int Endod J. 2001;34(3):221-230.

19. Haapasalo M, Shen Y, Qian W, Gao Y. Irrigation in endodontics. Dent Clin North Am. 2010;54(2): 291-312.

20. Vertucci FJ, Haddix JE. Tooth morphology and access cavity preparation. In: Hargreaves KW, Cohen S. Cohen's pathways of the pulp. Ch. 7, 10th ed. St. Louis: Mosby Elsevier; 2011.

21. Qualtrough AJ, Mannocci F. Endodontics and the older patient. Dent Update. 2011; 38(8): 559562, 564-566.

22. Gani O, Visvisian C. Apical canal diameter in the first upper molar at various ages. J Endod. 1999;25(10):689-691.

23. Abou-Rass M, Jastrab RJ.The use of rotary instruments as auxiliary aids to root canal preparation of molars. J Endod. 1982;8(2):78-82.

24. Smith AJ. Dentin Formation and Repair. In: Hargreaves KM, Goodis HE. Seltzer and Bender's Dental Pulp. Ch. 3. Chicago: Quintessence Publishing Co; 2002.

25. Can ED, Gerek M, Kayahan MB, Mohsenı K, Sunay H, Bayirli G. Comparison of two different preparation protocol of $\mathrm{Ni-Ti}$ rotary PathFile ProTaper instruments in simulated s-shaped canals. Acta Odontol Scand. 2014;72(1):76-80.

26. Berutti E, Cantatore G, Castellucci A, Chiandussi G, Pera F, Migliaretti G, Pasqualini D. Use of nickeltitanium rotary PathFile to create the glide path: comparison with manual preflaring in simulated root canals. J Endod. 2009;35(3):408-412.

27. Senawongse P, Otsuki M, Tagami J, Mjör I. Age-related changes in hardness and modulus of elasticity of dentine. Arch Oral Biol. 2006;51(6):457463.

28. Morse DR. Age-related changes of the dental pulp complex and their relationship to systemic aging. Oral Surg Oral Med Oral Pathol.1991;72(6):721-745.

29. Knowles KI, Hammond NB, Biggs SG, Ibarrola $\mathrm{JL}$. Incidence of instrument separation using Light Speed rotary instruments. J Endod. 2006;32(1):1416.

30. Wolcott S, Wolcott J, Ishley D, Kennedy W, Johnson S, Minnich S, Meyer J. Separation incidence of protaper rotary instruments: a large cohort clinical evaluation. J Endod. 2006;32(12):11391141.

31. Leseberg DA, Knowles K, Hammond N. Clinical incidence of endodontically treated teeth with nonretrievable rotary files. J Dent Res. 2005;84(Spec Issue A):abstract 1564.

32. Spili P, Parashos $P$, Messer $\mathrm{HH}$. The impact of instrument fracture on outcome of endodontic treatment. J Endod. 2005;31(12):845-850.

33. Al-Fouzan KS. Incidence of rotary ProFile instrument fracture and the potential for bypassing in vivo. Int End J. 2003;36(12):864-867.

34. Di Fiore PM, Genov KA, Komarrof E, Li Y, Lin L. Nickel-titanium rotary instrument fracture: a clinical practice assessment. Int End J. 2006;39(9):700708.

35. Cunha RS, Junaid A, Ensinas P, Nudera W, Bueno CE. Assessment of the separation incidence of reciprocating WaveOne files: a prospective clinical study. J Endod. 2014;40(7):922-924.

36. Iqbal MK, Kohli MR, Kim JS. A retrospective clinical study of incidence of root canal instrument separation in an endodontics graduate program: a PennEndo Database Study. J Endod. 2006;32(11):1048-1052.

37. Tzanetakis GN, Kontakiotis EG, Maurikou DV, Marzelou MP. Prevalence and management of instrumental fracture in the postgraduate endodontic program at the Dental School of Athens: A five-year retrospective clinical study. J Endod. 2008;34(6):675-678.

38. Madarati AA, Hunter MJ, Dummer PMH. Management of intracanal separated instruments. J Endod. 2013;39(5):569-581.

39. Parashos $\mathrm{P}$, Messer $\mathrm{HH}$. Rotary NiTi instrument fracture and its consequences. J Endod. 2006;32(11):1031-1043.

40. BoesslerC, Peters OA,Zehnder M. Impact of lubricant parameters on rotary instrument torque and force. J Endod 2007;33(3):280-283.

41. Shantiaee $Y$, DianatO, Sharifi F, Nahvi G, Kolahi Ahari G. The impact of three different canal lubricants on fracture, deformity and metal slivering of ProTaper rotary instruments. Iran Endod J. 2014;9(2):127-130.

42. Bürklein $S$, Tsotsis $P$, Schäfer E. Incidence of dentinal defects after root canal preparation: reciprocating versus rotary instrumentation. J Endod. 2013;39(4):501-504.

43. Liu R, Hou BX, Wesselink PR, Wu MK, Shemesh $H$. The incidence of root microcracks caused by 3 different single-file systems versus the ProTaper system. J Endod. 2013;39(8):1054-1056.

44. Yoldas O, Yilmaz S, Atakan G, Kuden C, Kasan Z. Dentinal microcrack formation during root canal preparations by different NiTi rotary instruments and the self-adjusting file. J Endod. 2012;38(2):232-235. 


\section{Anastassios Retsas}

DDS,

General Dental Practitioner, Athens, Greece

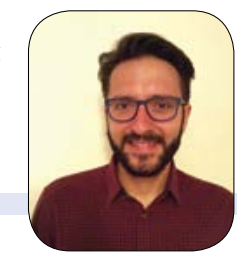

Anastassios Retsas was born in 1989 is Athens, Greece. He enrolled

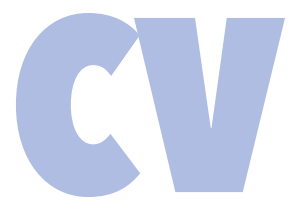

as a student of the Dental School of the National and Kapodistrian

University of Athens in 2007 and graduated in 2012. Thereafter he served as a dentist at the Hellenic Air Force for one year. He has also served as a volunteer dentist in many dental programs in Athens and has worked in dental offices specialised in Endodontics. He

has always been interested in the field of Endodontics, attending conferences and presenting papers on this topic area. He is currently working as a private dental practitioner in Athens and will soon start his postgraduate studies in Endodontics in ACTA.

\section{Ouestions}

\section{The older dental patients can be generally divided into the following groups:}

$\square$ a. Independent and frail older people.

$\square$ b. Fully dependent and frail older people.

$\square$ c. Independent older, frail and fully dependent older people

$\square d$. There are no specific patients' categories. We treat every dental patient older than 65 years of age according to similar principles.

\section{Endodontic procedures in geriatric patients :}

a. Should be completed in a single appointment, in order not to burden the patient with multiple visits.

b. Should be distributed in multiple and shorter appointments, in order not to burden the patient with long-duration procedures.

c. Should only be scheduled in the morning.

$\square \mathrm{d}$. Should be adapted to each patient's individual needs.

\section{Separation prevalence of rotary Niri instruments has shown to be :}

a. Greater than that of hand instruments.

$\square$ b. Less than that of hand instruments.

$\square$ c. Almost the same with hand instruments.

$\square$ d. No clinical instrument separation has been reported for rotary NiTi instruments.

\section{Specify a common problem when performing endodontic treatment in older} patients' teeth:

a. Local anesthesia is very difficult to perform.

$\square$ b. The teeth roots often present internal resorption.

$\square$ c. Rubber dam isolation placement is very difficult.

$\square$ d. Dentine deposition narrows the canal and makes access and patency very difficult. 